Matthews, J.H. \& Shulman, A.D. (2005) Competitive advantage in Public sector organizations:

Explaining the public good/sustainable competitive advantage paradox, Journal of Business Research, 58(2): 232-240.

\title{
Competitive advantage in Public sector organizations: Explaining the public good/sustainable competitive advantage paradox ${ }^{i}$
}

\author{
Judy Matthews \& Arthur Shulman \\ School of Management \\ The University of Queensland \\ j.matthews@gsm.uq.edu.au; a.shulman@gsm.uq.edu.au
}

Paper submitted to Journal of Business Research, Special Issue on Business-to-Business Relationship Architecture and Networks among Australian, New Zealand and Asian Firms (November 2000). 


\title{
Competitive advantage in Public sector organizations: Explaining the public good/sustainable competitive advantage paradox
}

\author{
Judy Matthews \& Arthur Shulman \\ School of Management \\ The University of Queensland \\ j.matthews@gsm.uq.edu.au; a.shulman@gsm.uq.edu.au
}

\begin{abstract}
Resource based views of the firm and in particular Kay's (1995) model of sustainable competitive advantage have been used to advance an understanding of differences in the competitive advantage of private sector firms. We extend the analysis to a public sector firm where its major purpose includes engaging in public good by giving away its knowledge base and services. The case highlights the paradox that many public sector organisations face in simultaneously pursuing public good and sustainable competitive advantage. While Kay's model is applicable for understanding intergovernmental agency competition, we find it necessary to incorporate Resource Dependency Theory to address the paradox. Implications for theory and practice are provided.
\end{abstract}




\section{Introduction}

Kay (1995) presents the notion of sustained competitive advantage in organisations obtained through relational architecture, reputation, innovation and strategic assets. At the core of Kay's model is the resource based theory of the firm which focuses on the internal attributes or the resources and capabilities of the firm where, in order for the resources and capabilities of a firm to provide superior performance, they must be (1) valuable in the sense of enabling a firm to exploit its environmental opportunities (and/or neutralise its threats), (2) rare among its current or potential competitors, (3) costly to imitate, and (4) without close strategic substitutes (Barney, 1991). Kay states that organizations have a strong architecture where there is an expectation of long-term relationships both within the firm and among its members, a commitment to sharing the rewards of collective achievement and a high but unstructured degree of informality. He contends that this architecture adds value to individual contributions of its members through the creation of organizational knowledge, through the establishment of a cooperative ethic within the organization and by the implementation of organizational routines.

For Kay (1995:27) and others (See the work of the IMP group, (Hakansson, 1982, 1987, 1989; Axelsson and Easton, 1992; Hakansson and Snehota, 1995; Moller and Wilson, 1995), good commercial relationships are fashioned through cooperation (joint activity towards a shared goal), coordination (the need for mutually consistent responses) and differentiation (the avoidance of mutually incompatible activities). However, Kay in passing, also suggests that the notion of sustained competitive advantage is relevant for understanding the differences in performances of non-profit organizations in situations, "where the added value or benefits are not retained by the firm, but instead are distributed to its members or the community" (Kay, 1995:174). Unfortunately Kay does not give attention to the paradox this raises where the purpose of the organisation is to create knowledge and services and give them away for the public good rather than maximising private profit.

\section{Competitive Advantage and Public Sector Firms - Exploring the Paradox}

According to the resource based theory of the firm, the basis of sustainable competitive advantage of a firm stems from its capabilities such as value, rareness, inimitability and organization (Barney, 1991, 1996) or more generally reputation, innovation, architecture and strategic assets (Kay, 1995). Successful private sector firms use their capabilities to add value by using these capabilities in a proactive way and by demonstrating appropriability, or the ability to realise the benefits of a distinctive capability for the benefit of the firm itself, rather than its customers, suppliers or competitors.

Public sector organisations and government departments are created to fulfil responsibilities of government and are expected to cooperate in the policy development and the delivery of services. In western societies, public agencies are often created under the guise of addressing market failure and are maintained to contribute to the common good. In the case of public sector $\mathrm{R} \& \mathrm{D}$, their role is also to contribute to the development of industry, and the creation of markets.

Most of the writing on competitive advantage, like the theoretical rationale for purchaserprovider forms of relationships, builds on agency theory. A general proposition of agency theory is that those in control of resources will serve their own interests, rather than those who own the resources (Stewart, 1999). In contrast, public sector organisations are created to develop and deliver service for the benefit of the populace. For example, public sector Agriculture R\&D organisations create knowledge of use to producers and other members of 
the supply chain, such as processors and distributors. Their purpose is not for commercial transactions to benefit a few, but to develop a sustainable capability of the industry in terms of efficiency and effectiveness. In the case of agriculture, the outputs and outcomes that are targeted include better strains of plant varieties suitable for the local environment or for specific end products, better practices which generate higher yield, and farming practices which value the whole environment and its sustainability.

Public sector organisations are funded from a central source of government funds, where the constraints of a largely 'fixed pie' creates competition with other government agencies for funding. Each firm must have resources and capabilities and must take into account their environment and negotiate with relevant sources of funding including Departments of Treasury for resources. In this sense they are largely dependent on their environment for resources. Most importantly, they are also dependent upon other bodies, such as Ministerial cabinets, for deciding on their direction and scope of operation. In comparison, private sector organizations have governance structures that provide direction and scope of operations that are intended to serve their own interests.

\section{Case study of Sun State Agriculture}

We investigate this paradox of sustainable competitive advantage where the purpose of the organization is to create knowledge and services and give them away for the public good rather than maximise private profit, in an Agriculture public science organization. We begin by using Kay's framework of architecture, reputation, innovation and strategic assets to identify the specific capabilities of the organisation and examine the effect on these capabilities over two recent phases of internal restructuring. These phases are the implementation of purchaser- provider relationships within the organization to create distinct business groups focused on distinct areas of $R \& D$ and secondly, bringing together the business units to form a new united and coordinated structure with other R\&D units focused on research and development.

\section{Methodology}

Our data was collected through 50 interviews with senior and middle management staff members, external stakeholders and observations and archival records over a two-year period. This collection occurred at the project, program, Institute (Business Group) and organisational levels of this State Government organization while it was undergoing restructuring.

\section{Sun State Agriculture}

The organisation under study is an Australian State Department of Primary Industries, in "Sun State", a large government organisation whose primary activities focus on research, development and extension (RD\&E), information services and regulatory functions serving fisheries, forestry and agriculture industries. The organisation's agricultural research involves research, development and extension, where extension is the name given to the dissemination of the results of the agricultural research with either no or little cost to the farming community. As a government organization, its major stakeholder is the government of the day. It's mission in 1998-999 was to be an "innovator and a responsible partner with the Food and Fibre Sectors of Sun State and to help industry meet the increasing demand of customers in domestic and export markets for higher levels of quality in the products and services they produce”. However, regardless of mission statements made by the Government of the day, senior executives of the organisation see its roles as fostering (rural) community development, economic returns and a sustainable environment. 
Sun State Department has an annual budget of more than $\$ 350$ million (AUS) and a workforce of over 4000 staff spread across a large geographic area. Agriculture is a leading contributor to Sun State's economy accounting for 36\% of the value of the State's overseas exports and 21\% of Australia's rural exports” (Sun State Annual Report, 1997-98). It is the largest of the seven Australian State/Territory Agricultural departments. Each of the these State/Territory government agricultural Research/ Science organisations compete with each other and with private sector providers for national research and development funds and overseas contracts. In Australia as elsewhere, a National Competition Policy in which a government agency must not engage in bidding practices that take undue advantage of their infrastructure being underwritten through the public purse, constrains their competitive behaviour.

Like many R\&D organisations in agriculture world wide, this organisation is operating in a very competitive 'mature' market, with a decreasing number of people engaged in rural production industries. The dynamic nature of challenges which this state faces include changes in technologies, an increasing consumer focus on ecological sustainability, and increasing global competition for supplying agricultural products, and declining funding from Government sources. Though not unique to government departments in Australia (Alston, Pardey, Philip, Roseboom, (1998), Byerlee (1998), Fuglie, Day, Klotz, Ollinger, Reilly, Vasavada, Yee, 1996) all of these forces have been pressuring senior management within this department to find ways to change its organisational arrangements to improve its efficiency and effectiveness.

The history of recent changes in Sun State Agriculture can be seen in Figure 1. In 1997, Sun State engaged in a structural realignment that was guided by a purchaser-provider model (FitzGerald, Charmichael, McDonough and Thornton, 1996). The purchaser-provider model was intended to separate the purchaser function from the provider function to improve accountability and transparency, and improve efficiency and effectiveness in the delivery of services and outcomes to targeted clients (Shulman, Wollin, Duffield, Steffens \& Wissemann, 1997).

The organisation's structure and governance were changed through the amalgamation of regional and discipline silo groups into industry focused R, D and E business "provider" groups or institutes (Shulman et al., 1997). At the time of this study, the organization had reorganised its RD\&E resources, including its approximately 800 research projects, into a statewide network of industry-based business institutes for beef, horticulture, farming systems, sheep and wool, and food technology. Each institute or business group, as a provider of RD\&E, formed partnerships within the department and externally with other organizations.

The main purchaser of these services was the Minister through his representatives (Director General and/or Industry Program Coordinators). The governance of each of these commercially focused industry Institutes was guided by an advisory board comprised of supply chain industry representatives who often occupied key positions in farming interest and lobby groups and/or were on Boards of commodity marketing or funding organisations. These representatives were to guide the direction of the business units. The Director General with the consent of the Minister appointed a Director for each Institute. The initial staffing of each Institute was comprised of staff that had previously been dispersed through the prior regional structure, but were engaged in on-going $R \& D$ projects in specific commodity areas.

In implementing this restructuring, these business groups were provided with a nonnegotiable core budget (block grant) from Departmental funds to cover inherited staff and projects. Many projects had at least 3 to 4 years of contractual work to be completed. In addition to the core budget, each RD\&E business unit was able and encouraged to seek competitive external funding, a practice previously engaged in by senior research scientists. Most of the opportunities for obtaining competitive funding were through Industry 
associations and research and development funding corporations that obtained $50 \%$ of their monies from commodity levies and 50\% from matching federal funds, and through international granting agencies as the World Bank. Their major Australian based competitors for these funds were usually six other national or state based Agricultural research Agencies or from research groups based in 38 Australian Universities. The success rate in winning these competitive funded projects varied considerably across Institutes/business Units. The majority, however, obtained $20-48 \%$ of their entire operating budget through these competitive mechanisms. But the bulk of their funding was from the Sun State Minister's office, and was largely based on historical formulae, a proportion of the resource funding to the larger Sun State primary industry organisation allocated by the state government and Treasury on the basis of historical performance in achieving specific objectives in the delivery of services.

In late 1999, the Minister announced that in response to an external review of the Institute structures, a integrative Food and Fibre provider Agency would be created to drive research in areas that go across the Industry based Sector Institutes (such as sustainability and biotechnology), and would demonstrate before the next election, that the Government was concerned about the long term future of the rural community. Under this restructure, the fund raising and research activities of each research Institute/ Business unit would be reviewed and guided by the Executive Director of the Food and Fibre Sciences Agency to maximise collaboration amongst the business units and to present a single public face on substantive new economic, environmental and community issues- for instance genetic modification and salinity.

\section{Analysis: Sustainable competitive advantage in public sector R\&D organisations}

Using Kay's criteria of innovation, reputation, architecture and strategic assets, we proceed to a more detailed analysis of the organisation and its business units to assess their progress towards sustainable competitive advantage over the last 18 months. We begin with innovation, reputation and strategic assets of Kay's model and then examine the architecture, using the three categories of relationship architecture outlined in Kay (1995), i.e. internal, external and network relationships further illustrate the opportunities gained by these changes for competitive advantage.

Innovation. Innovation in Kay's model usually implies both market and position. Both market and position are a focus of the organisation and its business units (Sun State Annual Report 1998-1999). Innovations have occurred in creating new market niches for existing products, and new products for existing markets, as well as the increased application of technologies used in other fields to agriculture. $R \& D$ has a developed a tighter value chain focus, from crop varieties to storage issues and pest management and the involvement of other stakeholders has increased.

Two of the five business groups are positioning themselves as leaders in their field in terms of breeding of particular crop varieties and in terms of developing proposals to be prime stakeholders for leading research centres in their areas of specialty. Others have become preferred providers for R\&D corporations. Kay's concept of innovation as relevant to both market and position clearly applies in public sector R\&D corporations.

Reputation. Kay (1995) argues that the reputation of a firm is created in a specific market. In an R\&D context, the reputation of the firm has a close relationship between the reputation of the scientists and the reputation of the organisation with consequences for relationships with stakeholders and funding bodies. The reputation of individual scientists had previously been well established and the formation of specific business groups built on the previous good 
reputations and thrust many into a more major role, providing opportunities to highlight the work of these scientists. Since the creation of specific business groups, some business groups rather than a project team become preferred suppliers, and on the basis of their reputations, have received direct invitations from external funding organisations to carry out specific RD\&E programs. Others have increased their sources of $R \& D$ funding from $R \& D$ corporations.

The nature of a firm's reputation is of course competitive and reflects the context of the organization and its relationships with others and closeness to the customer and reputation for the delivery of quality products and processes. The issue of reputation in a competitive world needs to be constantly renewed. Staff recognised the importance of reputation developing over time at all levels of the work unit as well as the role of project leaders, and the importance of reputation for receiving funding through interactions.

Strategic Assets. The business groups are responsible for the day-to-day running costs of the research stations and since the restructuring and tighter controls now manage these resources including knowledge resources and the commercialisation of intellectual property in a more comprehensive way. The business groups have become more commercial in focus, and are now undertaking more strategic decision-making regarding the direction of the business groups, the types of R\&D being undertaken and the strategic assets both human and physical required for now and the future. They have planned and contracted for the building of new laboratories, a building programme, and more bio-technological laboratories to extend their existing work. However to obtain the necessary resources for such capital works, the business groups must engage in lobbying and promotion of the present and future worth of their research programs. They have taken a more active communication and marketing role with their stakeholders, within their own organization with the CEO and the Minister.

\section{Structure}

The restructuring of the organisation into business groups improved the internal architecture of each research area through (i) the specific focus of each business unit on an identifiable industry that matched the domain of the federal industry Government granting body, and (ii) the establishment of an active advisory governance board for each business group that provides a commercial focus. Members on this advisory board were also chosen because of their positions with external funding bodies and lobbying groups. The advisory boards in particular have brought an accountability measured in outcomes.

Architecture. Architecture in Kay's model includes internal relationship architecture, external relationship architecture and network relationship architecture.

Internal relationship architecture: With the exception that some staff viewed the change in internal structure as just one more (ineffective) reshuffle of the card deck, many reported increased morale with the new business groups arrangements with an opportunity to take on more significant and larger projects with a clear set of objectives. This increased morale was confirmed in an organisational culture survey, (Sun State Report, 1999). For instance in one business group, staff articulated that working together with a common purpose and establishing teams with a focus on one commodity across regions brought together much of the knowledge and experiential practices that strengthened their delivery and their sense of identity.

External relationship architecture. For Kay, competitive advantage also flows from improvements in the architectures in place to guide the informal relationships between staff and those stakeholders outside of the organization. For Sun State Agriculture, the reorganisation of its internal structure had major impact on the rules and ways staff interacted with stakeholders. Some staff stated that the new focus on one area within each business groups gave them a clear point of contact from industry and gave instances that industry appreciated being able to 'go straight to the source'. These changes in access through the 
external architecture between the firm and suppliers or customers appears to have increased commercial relationships with businesses and a with more value chain target approach. The Advisory Board created for each business groups provided commercial expertise to the business group and encouraged tighter business practices as well as strengthening the links with industry members (Baker, Radcliffe \& Wissemann, 1999).

Network relationship architecture. Whereas the external relationship architecture addresses changes in 1:1 relationships, Kay also pointed out the strategic competitive advantage of strengthening the informal and implicit ways the organization generates advantages through forming multiparty alliances or networks of relationships. Our data suggests that external linkages with networks or between groups of collaborating firms have increased, with improved relationships with the R\&D corporations. Business groups established clear roles in the provision of $R \& D$, from the development of concept proposal negotiated with producers and sponsors, to the delivery of R\&D outcomes. Following a review of R\&D (Baker et al, 1999) within the last twelve months, these business units have loosely reassembled into a central agency to capitalise on their separate strengths and to rebuild synergy (Baker et al.1999). Historically, resource relations indicate increased provision as well as favoured status. After the restructuring into provider groups, the new departmental structure was driven more by cooperation and partnership, than by competition. This is not surprising. In traditional business networks, cooperation, adaptations, trust, commitment between actors develops slowly over time (Moller and Wilson, 1995; Ford et al. 1998: 25-30).

When the R\&D business groups were established, strong resource ties existed within the Departmental network. The most obvious were the common "corporate support" across the entire department, including common information systems, accounting systems, legal services, HR services, RD\&E policy advice, export development, and rural industry business services. These resources were spread across all business units across the whole department, with consequences for staff movements and implementing software to facilitate activity links. Strong physical resource ties also existed horizontally between the business groups. It is not uncommon for business groups/institutes to share sites and equipment and this shared space increases the potential for horizontal activity links between business groups.

This resource tie has been an important factor shaping the relationship between the business groups and the internal purchaser. More importantly, corporate identity influences the relationship between institutes and industry groups, since it is crucial in shaping the external perceptions of Institutes and providing a competitive advantage against other public sector $\mathrm{R} \& \mathrm{D}$ organisations for funding from $\mathrm{R} \& \mathrm{D}$ corporations and here their relational architecture, their track record of innovation, the reputation of its staff and strategic assets play important roles.

Kay argues that the architecture adds value to individual contributions through the 1) creation of organizational knowledge, 2) the establishment of a cooperative ethic, and by 3) the implementation of organizational routines. We examine each of these areas in relation to the business groups in Sun State agriculture.

The creation of organizational knowledge is an ongoing process and following the establishment of the business groups, the new organisational knowledge being developed is different to the prior operational knowledge and former routines. This knowledge development is more strategic in approach, setting research priorities with increased focus on their own research agenda and beginning to drive their own agenda.

The larger organisation has previously prided itself on its cooperative ethic ('Sun State' Annual Reports) and one of the benefits from the business group structure was the development of closer bonds with people within the business groups who were challenged to make each business group a financial as well as an R\&D success, while working within tight 
constraints. One consequence was that looser relationships with other parts of the original department developed.

New organisational routines. The restructuring into business groups and the new fiscal processes have challenged some of the prior organisational routines. New organizational routines for solving problems at a business group level, routines for financial management at a business groups level, routines for handling non-performance issues, routines for quality checking of project proposals prior to lodgement with external funding organisations have all been developed. Other processes such as increased focused on communicating and marketing outcomes of R\&D internally to the larger organization and to the CEO and Minister as well as other important stakeholders have taken longer to establish.

\section{Discussion}

The above case illustrates that the notions of sustainable competitive advantage based on distinct capabilities have some resonance with public sector R\&D organisations. The roles of public sector science organisations are not only to carry out research, development and extension with client groups and with industry bodies but also to compete with other public sector organisations and University based research groups for funds. However, it does not easily account for Governments' role in freely giving away its knowledge to create new industries or to engage in high risk and low immediate return on investment activities that address market failure nor does it adequately capture the all too common situation where an organization does not have control of its destiny, but is dependent upon the whims of an external body, in this case a Ministerial cabinet.

In both the competitive advantage and IMP frameworks, the importance of relationships with other firms and networks of firms as resources is recognized, but the case suggests that recognition alone does not provide an organisation with sufficient understanding of the constraints that the political and economic resource dependencies place on what its business is and the ways it can best structure itself to achieve business objectives. As highlighted in resource dependency theory, because organisations are not self-contained or self-sufficient, the organization's dependence on its environment makes the external constraint and control of organizational behaviour both possible and almost inevitable (Pfeffer \& Salancik, 1978). Frooman (1999) extends the resource dependency argument by viewing power as an attribute of the relationship between the actors. Resource dependence exists "when one actor is supplying another with a resource that is marked by 1) concentration (suppliers are few in number), 2) controllability, 3) nonmobility, 4) nonsubstitutability or essentiality. All of these attributes can be easily applied to the situation of 'Sun State'. For Frooman, the essentiality of a resource is itself a function of two factors: relative magnitude of exchange and criticality. For Public Sector organizations, their critical dependency on Ministerial cabinet decisions is legendary and tactics for shaping it are well documented in the long running episodes of "Yes Minister”.

We suggest that the inclusion of resource dependency considerations (Pfeffer \& Salancik, 1978) where differences in the dependence of a firm on its external stakeholders for resources provides one way to account for differences in the performance of public sector firms managing the competitive advantage paradox. It also helps address the issue of how firms can succeed in not only being guided by a profit motive, but by other triple bottom line considerations as serving community and the environment- for these objectives are those held by these controlling external stakeholders whose favour is essential. In the case of Sun State, the shifts in structures displayed in Figure 1 can be explained in terms of changing resource dependencies. It is these dependencies that limit the areas in which competition in the public sector is allowed and at times encouraged and where Kay's notions of strategic competitive 
advantage are applicable. While this case illustrates this need to include resource dependency contingencies when managing a public sector organisation, we believe that the lesson also holds for firms in the private sector in situations where there are restrictions on what businesses a firm can strategically collaborate with for instance, when there are single suppliers, where there no possibility of replacement Managers in both public sector and private sector firms focus on sustainable competitive advantage, using the resources and capabilities of their organisation and their coordination and application. While Kay's model articulates the components of this advantage including the internal and external relationships and the network of relationships as the architecture that it frames, managers also use their knowledge of resource dependencies of their organisations in choosing their objectives and means of obtaining them.

\section{Implications for managers and researchers}

The current form of the Sun State organisation attempts to maximise the resources of the firm in context of competition with other public sector agencies. The constraints these departments face as well as their competitive advantage can be explained by resource dependency. As private sector organisations move to more triple bottom line approaches where their ability to survive is tied to a certain extent with their reputation not just to profitability, we will find resource dependency arguments are increasingly applicable to the private sector. Kay's advice for improving private sector firm performance is not to engage in triple bottom line approaches "the less often that managers are forced to choose between corporate advantage and social concerns the better it will be for all "(Kay 1995: 234).

Our case study illustrates the weaknesses of his argument where organisations have mandated multiple objectives or have a restriction in choice of actions because of their dependencies for survival on a limited number of external constituents. For public sector organisations, established and funded to provide public good, these are not exceptions but the general case. Our analyses suggest that the notions of sustained competitive advantage and the resource based view of the firm do have some application for public sector organisations, but this application is limited to situations where competition is sanctioned and is possible. An implication of this is that managers is need to recognise that they are often simultaneously managing within multiple structures, some that fit Kay's notion of strategic competitive advantage, others that do not. These structures can (and do) co-exist to meet these different resource dependent objectives.

Resource dependency theory has much to add to the application of Kay's model for addressing issues of sustainable competitive advantage, whether the firm is in the public or private sector. However before this can occur more research is needed on ways that managers deal with sustainable competitive advantage notions alongside control systems or structures that have been put in place to achieve other objectives associated with public good.

\section{References}

Alston, J., M., Pardey, Philip, G., Roseboom, Johannes "Financing Agricultural Research: International Investment Patterns and Policy Perspectives” World Development, (1998) 26 (6): 1057-1071.

Axelsson, B. and Easton, G. (eds.) Industrial Networks: A New View of Reality. (1992) London: Routledge. 
Barney J.B. \& Hesterley, W. Organisational Economics: Understanding the Relationship between Organisations and Economic analysis. In Clegg, S.R. Hardy, C. \& Nord, W.R. Handbook of Organisational Studies. London. Sage. 1996, 115-147.

Barney, J. B. Gaining and Sustaining Competitive Advantage. New York: Addison-Wesley Publishing Company. 1997

Baker, J., Radcliffe, J. and Wissemann, A. An Evaluation of 'Sun State Primary' Industries Internal Institutes. 1999.

Barney, J. Firm Resources and sustained competitive advantage, Journal of Management, 1991, 17, 99-120.

Byerlee, D. “The Search for a New Paradigm for the Development of National Agricultural Systems” World Development (1998), 26(6): 1049-1055.

FitzGerald, V.W., Charmichael, J., McDonough, D.D. and Thornton, B. (1996), Report of the Queensland Commission of Audit, V1, Queensland Commission of Audit, Brisbane.

Ford, D., Gadde, L., Hakansson, H., Lundgren, A. Snehota, I., Turnbull, P. \& Wilson, D. Managing Business Relationships, (1998), Chichester: John Wiley \& Sons.

Frooman, J. Stakeholder Influence Strategies. Academy of Management Review, 1999, 24, 2, 191-205.

Fuglie, K. B.; N., Day; K.,Klotz, C.; Ollinger, M., Reilly, J.; Vasavada, U.; Yee, J.; "Agricultural Research and Development: Public and Private Investments Under Alternative Markets and Institutions” United States Department of Agriculture ${ }_{2}$ (1996) Washington, D.C.

Hakansson, H (Ed,) International Marketing and Purchasing of Industrial Goods: An Interaction Approach. Chichester: John Wiley and Sons. 1982.

Hakansson, H. Industrial Technological Development: A Network Approach. London: Croon Helm. 1987.

Hakansson, H. Corporate technological behaviour: Cooperation and networks, Routledge: London. 1989.

Hakansson, H. \& Snehota, I. (eds.) Developing Relationships in Business Networks. London: Routledge. 1995.

Kay, J. Why Firms Succeed. Oxford: Oxford University Press. 1995.

Moller, K. and Wilson, D. (eds.) Business marketing: An interaction and network perspective (1995), Boston: Kluwer p139-156.

Niosi, J. Fourth-Generation R\&D: From Linear models to Flexible Innovation. Journal of Business Research, 1999, 45, 111-117.

Hakansson, Hakan and Snehota, Ivan (eds.) Developing Relationships in Business Networks. (1995) London: Routledge. 
Pfeffer, J. \& Salancik, G.R. The external control of organizations: the resource dependence perspective. New York: Harper \& Row. 1978.

Shulman, A. D. , Wollin, A., Duffield, B., Steffens, P. \& Wissmann, A. "Institutionalisation of Purchaser-Provider models in public-sector agricultural research, development and extension: Gateways or shackles?” ARC SPIRT Research Grant. 1997.

Stewart, J. Research Note: Purchaser-Provider- Are the Purchasers Ready for it? Australian Journal of Public Administration, (December 1999) 58, (4) 105-111.

'Sun State’ Annual Report 1997-98

‘Sun State’ Annual Report 1998-99

1.This research is funded under an Australian Research Council SPIRT Grant "Institutionalisation of purchaser-provider models in agricultural R,D\&E: Gateways or shackles?” (1998-2000), awarded to A. D. Shulman, A. Wollin, B. Duffield, P, Steffens and A. Wissemann 


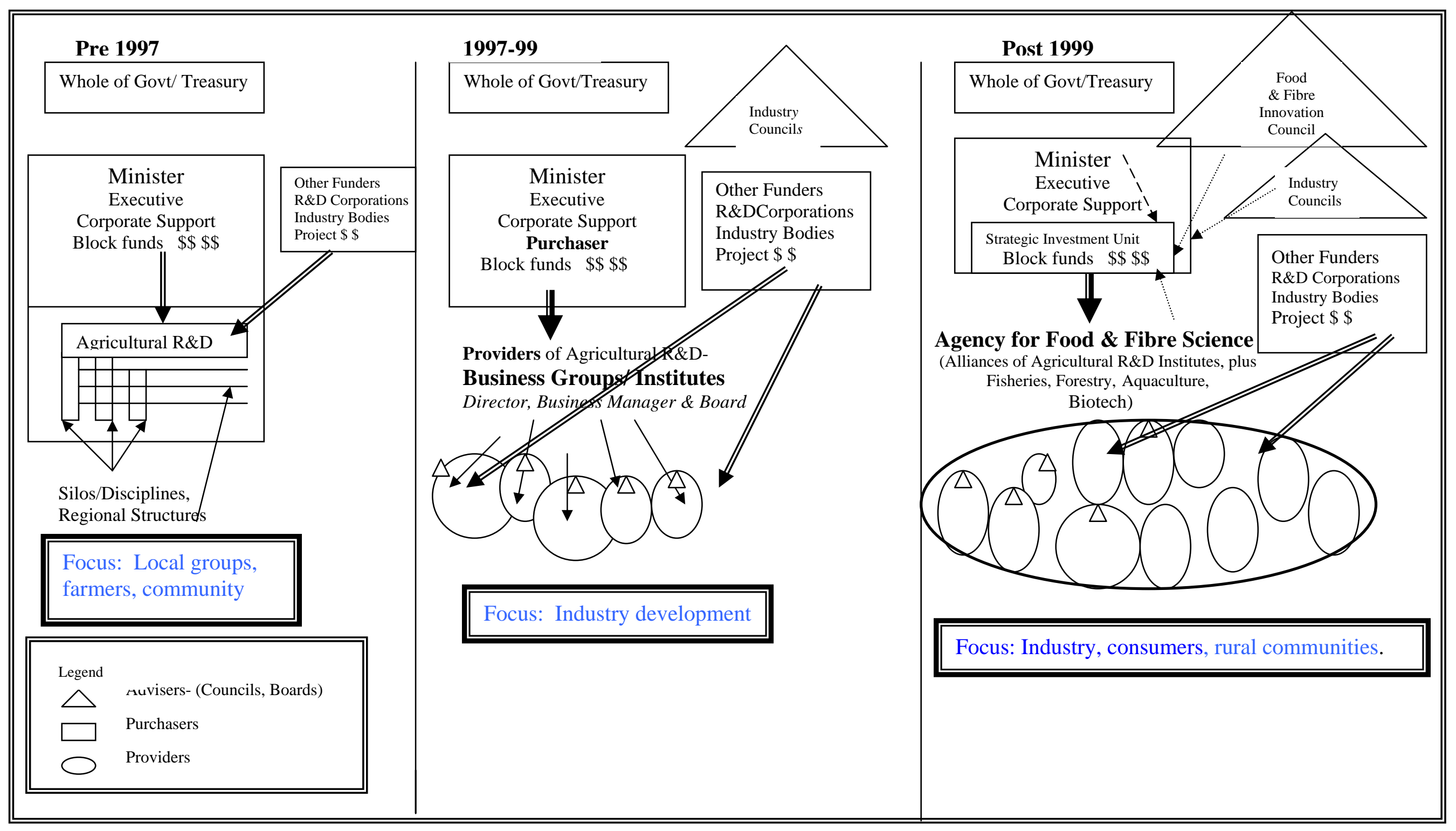

Figure 1. Changes in Sun State Agricultural RD\&E from pre 1997 where scientific disciplines were distributed through Regionalised structures, to 1997-99 Industry Institute/ Provider Business groups, to post 1999 Agency of Food and Fibre Sciences as a coordinated Alliance of R\&D Institutes/Business groups. 